\title{
In Memory of Professor Bazdawi Al-Riyami, MD
}

\author{
Omar A. Al-Rawas
}

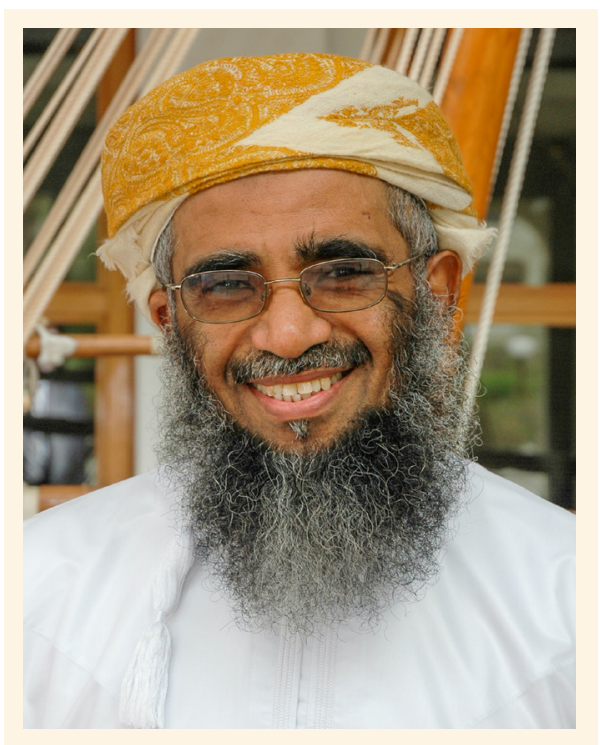

I

T IS A GREAT PRIVILEGE TO REFLECT ON MY ASSOCIATION with the mentor and colleague, Professor Bazdawi Al-Riyami who passed away on September 28, 2021.

I first met Prof. Bazdawi in 1984 in Glasgow, Scotland, during my undergraduate studies at the University of Glasgow, where he was doing his Ph.D. in respiratory medicine. I have been privileged to have him as a great coach who has contributed to shaping my professional development throughout my career. He was generous with his time, knowledge and spirit and was always ready to share his experience with remarkable wisdom, humility and encouragement. He was a role model to many healthcare providers in Oman.

Prof. Bazdawi completed his medical degree at the University of Baghdad, Iraq, and started his career as a junior doctor at Salalah Hospital, Dhofar region, in 1972. Two years later, he received a government scholarship to complete his general professional training in the United Kingdom. He acquired the Membership of Royal Colleges of Physicians in 1976 and returned to Oman in 1977 to work as a senior specialist in the Ministry of Health. In 1984, he joined the Sultan Qaboos "University Project" and was awarded another scholarship for higher professional training. He obtained his Ph.D. degree from the University of Glasgow in 1988 and the same year he was elected a Fellow of the Royal Colleges of Physicians and Surgeons of Glasgow; he then rejoined Sultan Qaboos University (SQU) as an Associate Professor in the College of Medicine and Health Sciences (COM-H) and a consultant in SQU Hospital (SQUH). He was promoted to full professor in 2004.

Prof. Bazdawi was instrumental in advancing teaching and research at SQU. For this, he was the primary mover and shaker of introducing a new curriculum that resonated with the situation on the ground. Oman at that time was witnessing a rapid social and economic transformation coinciding with the Al Nahda era or Renaissance. When this era is gleaned via the theory of demography in transition, Oman was experiencing all the key components of the 'second phase' of demography transition - a decline in maternal and child mortality and the traditional enemy of health (communicable diseases). However, rising living standards have led to new challenges, namely the rise of non-communicable diseases. Therefore, the existing model of health services in Oman-top-down, professionallydriven and cure-oriented-was becoming incapable to withstand the vagary of a new assortment of health problems. Within such a sociodemographic trend and the disease pattern in the country, Prof. Bazdawi embarked to revise the curriculum and research to better fit these changes. On the teaching front, the new curriculum was patched-up with the sole aim of addressing the demographic trend and emergence of diseases of affluence. He has been instrumental in expanding the scope of the COM-H by establishing a full-fledged BSc in Biomedical Sciences and the College of Nursing. Thus, the medical school becomes COM-H. Corollary to this, research infrastructure was established under his leadership to kick-start medical research at SQU-the establishment of SQUMJ as well as an institutional review board to the SQU that adheres to an evidence-based ethical approach.

To date, seeds planted in teaching and research by Prof. Bazdawi have come to fruition. The curriculum he established has produced a new breed of competent physicians in the country. The research he has orchestrated has improved by leaps and bounds. As a result, SQU is increasingly becoming a hub of international research collaboration and excellence in teaching.

Prof. Bazdawi's contribution to healthcare in Oman emerged by his personality marked with dedication, passion, patience, wisdom and thoughtfulness. The country and medical fraternity is saddened by the loss of one of the finest physicians, leader and team-maker. His legacy will remain an inspiration for generations to follow. He is survived by his beloved companion, his wife (Muheira Nasser Al Mugheiri), his daughters (Nafila, Hanan and Maryam), his sons (Usama, Ahmed and Mohamed) and his grandchildren. 